\title{
Sistema online de gerenciamento projetual como recurso na avaliação de projetos em Design
}

Heli Meurer - heli_meurer@uniritter.edu.br - Pós-Graduação em Design/UniRitter

Eliseo Berni Reategui - eliseoreategui@gmail.com - PPGIE/UFRGS

Patricia Alejandra Behar - patricia.behar@ufrgs.br - PPGIE/UFRGS

Lydia Helena Wöhl Coelho - lydiacoelho@gmail.com - Pós-Graduação em Design/UniRitter

Carla Pantoja Giuliano - carla_giuliano@uniritter.edu.br - Pós-Graduação em Design/UniRitter

Resumo: Este estudo apresenta considerações sobre resultados de um experimento prático, realizado com alunos e professores de Design, em disciplinas de Projeto de diferentes Instituições de Ensino Superior (IES) do Rio Grande do Sul e Santa Catarina, no ano de 2014. O objetivo é verificar a influência da ferramenta de avaliação de um sistema de gerenciamento de projeto no ensino de Metodologia Projetual em Design, que utiliza Aprendizagem Baseada em Projetos (ABP). Para isso, os professores e os alunos das IES envolvidas participaram de uma tarefa projetual, com duração de um semestre letivo. Após o término desse semestre, alunos e professores comentaram suas experiências. Em análise, concluiu-se que o sistema de avaliação permitiu que se acompanhasse a evolução dos projetos, favorecendo a avaliação satisfatória dos mesmos.

Palavras-chave: Avaliação em ABP, Metodologia Projetual, Design

\section{Online projects management system as a resource to Design projects evaluation}

\begin{abstract}
This article presents considerations about a practical experiment with students and teachers of Design from different Higher Education Institutions (HEIs) of Rio Grande do Sul and Santa Catarina, held in 2014. The objective of this study is to verify the influence of an assessment tool of a project management system for Design Project Methodology teaching, using Project-Based Learning (PBL). In this regard, professors and students of the HEIs involved participated in a project task with a duration of one semester. After the end of the semester, they expressed their opinions about the experience: students through questionnaires; professors through interviews. The analysis of data collected demonstrates that the evaluation system allowed to monitor the development of projects, in order to favoring satisfactory results of it.
\end{abstract}

Keywords: Evaluation in PBL, Project Methodology, Design

\section{Introdução}

O presente estudo apresenta resultados de um experimento realizado no primeiro semestre de 2014 envolvendo alunos e professores de Design, que atuam nas disciplinas de Projeto, em quatro Instituições de Ensino Superior (IES), no Rio Grande do Sul e em Santa Catarina. O experimento realizado foi de amplo escopo, cuja análise foi baseada em características pertinentes ao processo de Aprendizagem Baseada em Projetos (ABP), quais sejam: planejamento, investigação, autonomia, discussão, reflexão, colaboração, organização, projetação, apresentação e avaliação. Ressalta-se que, devido à extensão do experimento, bem como à grande quantidade de fatores envolvidos e à amplitude dos dados obtidos, neste artigo serão abordados somente os resultados 
relacionados ao processo avaliativo. Inclui-se, aí, o modo como esse foi beneficiado pela ferramenta correspondente, disponível em um sistema online de gerenciamento de projetos, chamado Projeto em Ação ${ }^{1}$.

Os professores e alunos envolvidos no experimento participaram de uma tarefa projetual, configurada de acordo com estratégia pedagógica proposta pelos pesquisadores. Tal tarefa teve a duração de um semestre. Aos professores, coube os seguintes procedimentos: gestão projetual, orientação de projetos e avaliação dos alunos; já aos alunos, coube: organização em equipes e realização das atividades previstas pelos professores. Antes do término do semestre, ambos expressaram suas experiências e opiniões sobre o uso do sistema educacional, tendo-se empregado, para isso, questionários respondidos pelos alunos, e entrevistas realizadas com os professores.

Este estudo está dividido em quatro (4) partes. Na primeira, apresenta-se o referencial teórico sobre Aprendizagem Baseada em Projetos (ABP) e suas formas de avaliação, bem como as funcionalidades do sistema online de gerenciamento de projetos em Design, que segue os requisitos encontrados no referencial teórico. Na segunda parte, apresenta-se o experimento realizado junto aos professores e alunos das IES, no âmbito das disciplinas de Desenvolvimento de Projeto em Design. Na terceira, são expostos os resultados obtidos por intermédio do experimento realizado, acompanhado de discussão sobre os mesmos. Por fim, na quarta parte, são extraídas as considerações finais.

\section{Referencial Teórico e Material}

Esta seção tem por objetivo apresentar o referencial teórico utilizado para a realização da pesquisa, bem como a descrição das funcionalidades do sistema online de gerenciamento de projetos em Design. Em sendo assim, ela está dividida em: i) revisão teórica sobre Aprendizagem Baseada em Projetos (ABP); ii) apresentação teórica sobre modos de avaliação no contexto da ABP, caracterizada como contínua e progressiva; e iii) descrição das funcionalidades da ferramenta avaliativa do sistema online de gerenciamento de projetos, configurada conforme a revisão teórica das subseções anteriores.

\subsection{Aprendizagem Baseada em Projetos}

A Aprendizagem Baseada em Projetos (ABP), de acordo com Gonzales (2004), é um modelo ou uma metodologia educacional, que promove a realização contextualizada e planejada de atividades em situações reais ou simuladas. Segundo Markham (2012), tal atividade pode ser compreendida como uma estratégia. Qual seja sua especificidade modelo, metodologia ou estratégia -, a ABP tem por objetivo estruturar a resolução de problemas relacionados à criação de serviços ou desenvolvimento de produtos, fazendo, dessa estruturação, um processo de aprendizagem. Tal aprendizagem, segundo Larmer e Mergendoller (2010), é iniciada pelo confronto com questões norteadoras instigantes, abrangendo conteúdos significativamente interessantes. Tais questões têm o intuito de motivar os alunos a realizarem investigações de longo prazo, de maneira autônoma e conjunta, em equipes (MARKHAM et al., 2008).

A estruturação da ABP é de ordem interdisciplinar e construtivista, de acordo como Milentijevic et al. (2006) e Markham et al. (2008), e engloba distintas estratégias de

\footnotetext{
${ }^{1}$ Plataforma Projeto em Ação. Disponível em <http://www.projetoemacao.com/> Acesso em 12/10/2016.
} 
ensino, a fim de facilitar a descoberta de novas possibilidades, planejamento, aplicação e demonstrações práticas daquilo que foi aprendido. Para Begay et al. (2006), o foco da ABP se concentra no processo de desenvolvimento das tarefas; ou seja, na realização de atividades práticas. Dada tal importância, as atividades práticas devem ser avaliadas de forma contínua e progressiva, pelo professor.

\subsection{Avaliação contínua e progressiva na $A B P$}

Em ABP, a avaliação ocorre constantemente durante o projeto e é feita pelo professor, mas também pelos alunos e pelos próprios colegas. Boss e Krauss (2007) destacam que um projeto complexo requer variados métodos avaliativos, de caráter formal e informal. Os autores apresentam cinco (5) categorias de avaliação, que abrangem: (1) monitoramento, através de listas de verificação, inventários, partes ou a totalidade do projeto; (2) observação, assistência e escuta ao que os alunos têm a dizer; (3) interação, para incentivar os alunos a pensar mais profundamente; (4) análise e coleção de artefatos do aprendizado do aluno; e, por fim, (5) relato e compartilhamento de dados de performance com os alunos, seus pais e outros.

Para Markham et al. (2008), a avaliação em ABP deve estar alicerçada ao desempenho discente, apresentando desafios rigorosos, capazes de comunicar altas expectativas. Larmer e Mergendoller (2010) concordam com tal consideração, acrescentando que o feedback e a revisão por intermédio do monitoramento do processo de desenvolvimento dos produtos, por parte do professor, são cruciais para que os alunos atinjam resultados satisfatórios. Por isso, todo material que tiver sido desenvolvido pelas equipes, tais como anotações de pesquisa, rascunhos e planos de ação, além de servir aos fins do próprio estudo, pode também ser instrumento de monitoramento e avaliação do progresso da equipe.

Ainda segundo Larmer e Mergendoller (2010), o processo de revisão e resposta durante um projeto pode trazer maior significado para a aprendizagem, uma vez que a geração de bons resultados é um propósito importante do empreendimento. Para complementar as colocações de Larmer e Mergendoller (2010), Moursund (2004) defende que, devido à importância da geração de resultados no processo, a seleção de áreas de conteúdo e temas que serão abordados nos projetos deve partir da iniciativa discente; porém, o professor deve se certificar de que os alunos compreendem a importância do que estão fazendo. Para isso, conforme o autor, os alunos também podem ajudar a estabelecer objetivos e métodos de avaliação a serem utilizados.

Todas essas características da ABP contribuem para que o aluno se motive e se comprometa ativamente no desenvolvimento de seu projeto. De acordo com Moursund (2004, p. 7), "O êxito da ABP requer um alto nível de compromisso e motivação interna". Nesse sentido, Meurer e Szabluk (2012) sugerem que as equipes desenvolvam um relatório de projeto; pois, assim, o processo projetual poderá ser revisado e avaliado repetidamente, tanto pelo professor quanto pelos alunos e seus colegas de equipe. Esses autores destacam que, com isso, os alunos podem observar e avaliar seus processos criativos e a evolução dos mesmos - sendo essa a principal função dos relatórios. Neles, as equipes descrevem e apresentam todos os métodos, técnicas de planejamento e geração de alternativas utilizados nos projetos.

Larmer e Mergendoller (2010) também ressaltam que é importante que os produtos resultantes dos projetos possam ser apresentados publicamente para a escola, colegas, pais e pessoas interessadas, ou que de alguma forma estiveram envolvidas no projeto, 
seja pela atuação direta ou indireta. De acordo com eles, nas apresentações abertas, os alunos podem perguntar e refletir sobre como eles executaram seu projeto. Além disso, podem refletir acerca de possíveis novos passos, sobre conhecimentos adquiridos e habilidades desenvolvidas. De acordo com os autores, as atividades escolares são mais significativas quando os alunos apresentam seus trabalhos não como forma de testes, mas para um público real. Assim, eles se preocupam mais com a qualidade e a autenticidade de suas produções. Estes, segundo os autores, podem tanto replicar tarefas já feitas por profissionais como também criar produtos reais que sejam utilizados fora do ambiente de aprendizado.

\subsection{A Ferramenta de avaliação no sistema de gerenciamento projetual}

O sistema de gerenciamento projetual, utilizado para a realização deste experimento, trata-se de uma plataforma online no formato de Ambiente Virtual de Aprendizagem (AVA). Esta, tem por objetivo gerenciar projetos em Design no âmbito do ensino. Esse sistema foi desenvolvido para atender aos requisitos e necessidades da $\mathrm{ABP}$ - o que inclui o processo avaliativo. Visto que, para tal objetivo, há a impossibilidade de definir um único ambiente estratégico para orientar diferentes projetos, o sistema foi estruturado para agrupar várias equipes de projeto, num ambiente compartilhado por elas. Esta funcionalidade facilita a orientação e o assessoramento dos projetos por parte do professor e, devido ao fato de os alunos se encontrarem em um único ambiente, favorece a interação e a colaboração entre as equipes.

Os requisitos considerados importantes na estrutura projetual são: permitir que o professor defina e edite livremente o ambiente estratégico para o desenvolvimento de projetos, denominado, no sistema, de "Assunto Projetual"; possibilitar que o professor convide alunos para participar do(s) seu(s) Assunto(s) Projetual(ais); permitir que o professor convide outros professores para que se tornem co-orientadores e que seus alunos interajam entre si; oportunizar, aos alunos, a criação de seu perfil para que possam ser facilmente identificados; permitir a livre escolha e adoção de metodologias, métodos e técnicas, por parte do professor; dispor de dispositivo de recomendação relacionado às atividades dos alunos; apresentar metáfora cronológica para que professores e alunos observem o andamento dos projetos em relação aos prazos específicos e gerais; viabilizar a orientação e a avaliação contínua e progressiva através de caixas de comentários; assegurar a comunicação em tempo real entre os membros da equipe, de todos os alunos entre si e com o professor para que possam manter contato e realizar atividades mesmo fora do horário de aula; entre outros aspectos de interação entre professores e alunos.

De acordo com Cybis et al (2010), é importante, para a usabilidade do sistema, que o mesmo seja coerentemente estruturado e hierarquizado. Assim, as tarefas e as funcionalidades se tornam simples, objetivas e fáceis de serem usadas, tanto pelo professor quanto pelos alunos. O fluxograma do sistema é relativamente simples: conforme pode-se observar na Figura 1, o processo tem início com o cadastro do professor. Uma vez cadastrado, o mesmo inicia o planejamento e a gestão de sua estratégia criando um Assunto Projetual. Num primeiro momento, o professor define uma denominação, uma descrição e um período de duração para tal Assunto Projetual. Em seguida, ele estabelece uma ou mais etapas projetuais. Estas, também requerem nome, descrição e período. Ressalta-se, que o professor poderá incluir e editar etapas durante toda a duração do Assunto Projetual. 
Figura 1: Fluxograma do Sistema online de gerenciamento projetual para o ensino de desenvolvimento de projetos em Design.

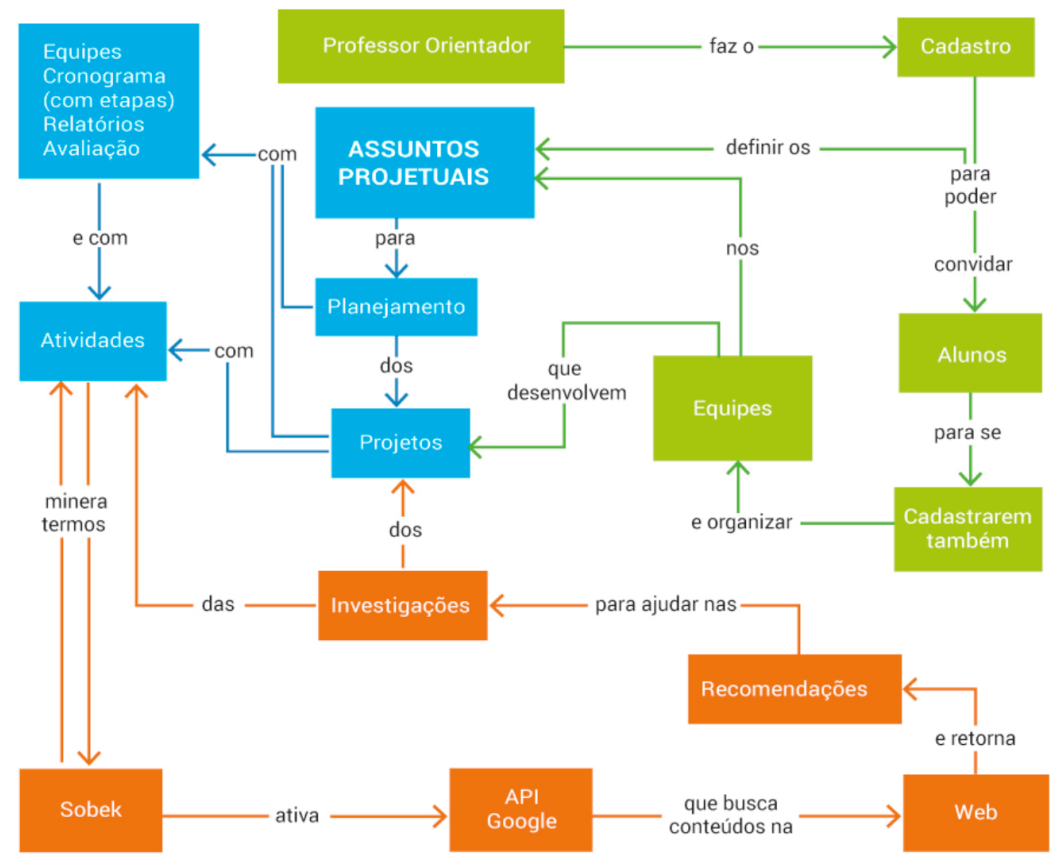

LEGENDA

Cadastro $\square$ Recomendação $\square$ Planejamento e projetação

Fonte: Meurer (2014).

Ainda de acordo com a Figura 1, nota-se que, num terceiro momento, o professor convida os alunos para que desenvolvam seus projetos de acordo com a macroestrutura estabelecida. Após receberem o convite, os alunos poderão se cadastrar no sistema e editar seus perfis. Porém, antes de começar os procedimentos projetuais, o professor poderá ajudá-los a organizar suas equipes e orientá-los na criação de suas primeiras atividades operacionais relacionadas às etapas. Somente na realização das atividades, propriamente ditas, é que as equipes irão desenvolver os métodos e técnicas oriundas da metodologia projetual adotada na estratégia. É importante que os alunos fiquem atentos aos objetivos de cada etapa para que os métodos e técnicas sejam escolhidos adequadamente.

Por último, o professor poderá convidar outros professores a fazer parte do Assunto Projetual por ele criado. Caso aceitem, estes assumirão o papel de co-orientadores e terão as mesmas licenças de edição do professor da disciplina. Professores convidados podem ser de diferentes instituições e localidades.

A principal estrutura desse sistema, conforme destaque dado na Figura 1, é o já mencionado Assunto Projetual. Este, trata-se de um ambiente virtual, no qual o professor define o tema, as metas, a macroestrutura metodológica (etapas) e o período em que será desenvolvido um projeto por determinado grupo de alunos. Nesse ambiente, todas as equipes atuam mediante as mesmas especificações gerais; porém, definem e desenvolvem suas atividades de maneira autônoma e independente. Portanto, os Assuntos Projetuais estabelecem a base para a mediação e o apoio ao processo criativo, compondo, entre outras questões, também um padrão de ações. Isso quer dizer, que se trata de um modelo estratégico para orientar as equipes em suas atividades. $\mathrm{O}$ 
Assunto Projetual oportuniza a formatação e a inclusão dos seguintes elementos e indivíduos:

- Estrutura cronológica com etapas (definidas pelo professor) e atividades (definidas pelo professor e/ou pelos alunos): cada etapa permite a inclusão de várias atividades. Tais atividades só podem ser efetivamente desenvolvidas pelos alunos; nelas, o sistema recomenda conteúdos específicos para cada pesquisa. A estrutura cronológica organiza as atividades em forma de metáfora visual, indicando a posição das mesmas na tela, de acordo com suas respectivas datas de início e fim.

- Professor(es): criam o Assunto Projetual, podendo incluir outros professores, que assumirão as mesmas permissões. O sistema usa o princípio da expansão baseada na colaboração mútua (Donnelly, 2005). Professores de diferentes cidades e instituições podem integrar seus alunos por meio da organização de um Assunto Projetual e, dessa forma, expandir suas interligações e interações para além do limite territorial ou da própria instituição.

- Alunos organizados em equipes (Boss e Krauss, 2007): podem ser organizadas pelo professor ou pelos próprios alunos, que, por sua vez, passam a ter autonomia para reorganizá-las, caso assim o desejarem. Uma vez criadas, as equipes desenvolverão distintas atividades projetuais com relativa liberdade, sempre sob as especificações do Assunto Projetual do qual fazem parte.

- Relatórios dos projetos dos alunos: seguem a estrutura de etapas definida pelo professor, permitindo uma visualização estruturada e sistematizada de todas as atividades desenvolvidas pelos alunos. Eles podem ser vistos, comentados e respondidos por todos os membros do Assunto Projetual (professores e alunos). Os comentários e respostas facilitam a contribuição e a colaboração inter-equipes, através de sugestões, dicas e referências.

- Avaliação de projetos: fica disponível para o professor e para os alunos da equipe, cujo projeto é avaliado, possibilitando que o professor faça seus comentários avaliativos em cada uma das atividades realizadas. A ferramenta ainda permite que os alunos requeiram ou respondam online as avaliações realizadas pelo professor, para que, intermediada por ela, tirem dúvidas, solicitem mais detalhes e/ou confirmem a orientação recebida.

Quando o Assunto Projetual é finalizado, o sistema permite que os relatórios dos projetos desenvolvidos sejam publicados (mediante permissão e consentimento das equipes). Uma vez publicados, podem ser livremente acessados por outros professores e alunos e, consequentemente, tornam-se referência para outros projetos.

\section{Método}

O estudo aqui desenvolvido pode ser classificado como pré-experimental, pois não recorre a um grupo de controle e nem possui uma forma padrão, com participantes, instrumentação e materiais, procedimentos e medidas, conforme definido por Creswell (2010).

Para a realização do experimento foram convidados cinco (5) professores de disciplinas de Projeto, incluídas nas matrizes curriculares de quatro diferentes faculdades de Design nos estados Rio Grande do Sul e Santa Catarina. Esses docentes coordenaram o experimento junto a seus alunos, e serão aqui denominados como professores A, B, C, 
D e E. Os mesmos foram selecionados de acordo com as características consideradas aderentes às especificidades do experimento. Isso significa, que foram escolhidos por professores com relativa fluência digital (conhecimentos em TIC), com formação em Design ou em Desenho Industrial. e com experiência de, no mínimo, dois (2) anos em disciplinas de desenvolvimento de projetos. No total, participaram 76 alunos. Mesmo com os devidos consentimento e esclarecimento dos mesmos, optou-se por mantê-los no anonimato, assegurando maior confidencialidade de seus dados. A fluência digital também constituiu como pré-requisito para a participação dos alunos.

No início do primeiro semestre letivo de 2014, após se cadastrarem no sistema educacional online e receberem o respectivo manual de uso, os professores convidados iniciaram seus usos do sistema. Primeiramente, estabeleceram o Assunto Projetual, de acordo com a estratégia pedagógica proposta para que este servisse de referência no desenvolvido dos projetos dos alunos, durante todo o semestre. Uma vez convidados e cadastrados, os se alunos organizaram em equipes, iniciando o processo projetual, propriamente dito. Seus projetos foram executados sob o formato de atividades, métodos e técnicas propostas pelo modelo de ABP. Devido à complexidade dos projetos, a duração de todo o experimento foi de um semestre letivo. Segundo Schwalm e Tylek (2012), na ABP de nível avançado é comum as investigações de longo prazo assumirem este período de tempo. Durante o processo projetual, as ferramentas do sistema foram utilizadas pelos alunos e professores, em diversas ações, incluindo a avaliação descritiva e recíproca de todas as atividades realizadas.

A coleta dos dados foi realizada por meio de questionários com os alunos e entrevistas com os professores, conforme descrito abaixo.

- Questionários: o instrumento quantitativo utilizado na coleta de dados corresponde ao questionário aplicado com os 76 alunos envolvidos no experimento. Esse questionário teve por objetivo identificar o nível de concordância dos alunos com afirmações feitas a respeito do uso do sistema educacional online. Para isso, empregouse uma escala de Likert ${ }^{2}$ com mensuração ordinal (GIL, 2009). Ou seja: os rótulos da escala estão relacionados entre si e são exibidos de forma ordenada. Deste modo, fica claro, ao respondente, em que direção os valores crescem ou diminuem. Os valores foram definidos em: 'Concordo totalmente, Concordo, Não concordo nem discordo, Discordo, Discordo totalmente'. Gil (2009) ressalta que, os valores possíveis para as variáveis devem ser equilibrados entre as possibilidades de avaliações positivas e negativas, incluindo uma avaliação neutra entre elas, no caso: 'Não concordo nem discordo'. No total foram treze (13) afirmativas relacionadas a diversos aspectos, incluindo uma questão sobre a importância do sistema no amparo do próprio processo avaliativo.

- Entrevistas: para confrontar ou confirmar as respostas fornecidas pelos alunos, em seus questionários, os cinco professores que participaram da pesquisa (classificados em A, B, C, D e E) foram entrevistados com auxílio de um roteiro baseado no questionário dos alunos. As entrevistas realizadas buscaram coletar dados

\footnotetext{
${ }^{2}$ Conjunto de itens apresentados como afirmações ou opiniões, para os quais se pede uma reação dos participantes. Ou seja, apresentamos cada afirmação e pedimos ao sujeito que manifeste sua reação escolhendo um dos cinco pontos ou categorias da escala. Para cada ponto atribuímos um valor numérico. Assim, o participante obtém uma pontuação pela afirmação e no final sua pontuação total, somando as pontuações obtidas em todas as afirmações" (SAMPIERI et al., 2013 p. 261).
} 
qualitativos acerca das percepções dos professores em relação às suas experiências, durante o experimento.

\section{Resultados e Discussão}

Para análise do experimento, os dados coletados por meio de questionários foram transpostos para criar gráficos que apresentam o percentual das respostas dos alunos, conforme apresentado na Figura 2.

Figura 2: Resultados obtidos por meio de questionários com os alunos.

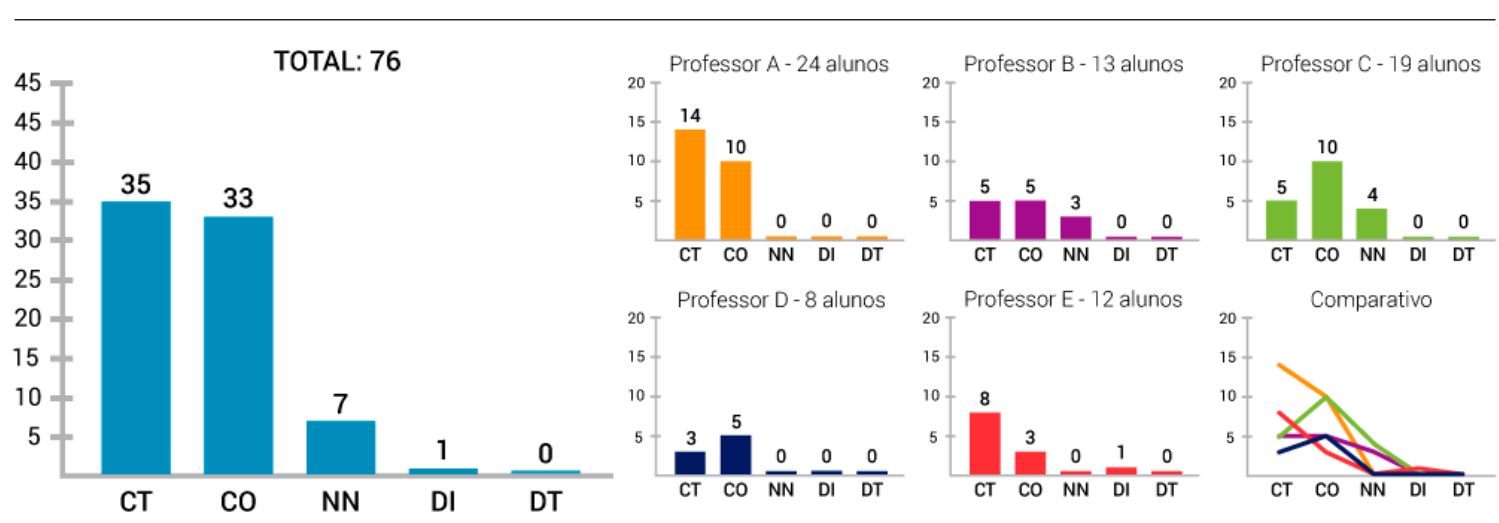

Legenda

CT - Concorda totalmente Co- Concorda $\quad$ NN - Não concorda nem discorda $\quad$ DI - Discorda $\quad$ DT - Discorda totalmente

Fonte: Meurer (2014).

Na figura acima, pode-se observar que, para 68 (89,5\%) dos 76 alunos, é importante uma avaliação dialógica entre professor e alunos, empregando-se comentários e respostas. Poucos alunos se manifestaram de forma neutra; os maiores índices foram três (3) respostas no grupo do professor B, e quatro (4) no do professor C. Somente um aluno discordou, em toda a pesquisa, e nenhum discordou totalmente. Acredita-se que a tendência expressivamente positiva foi decorrente de dois fatores: o primeiro diz respeito à importância que os alunos atribuíram a um feedback contínuo e pontual; e o segundo está associado ao fato de o sistema realmente ter facilitado a interação e o diálogo professor-alunos, conforme também foi constatado nas entrevistas com os professores.

Para o professor D, a interação oferecida pelo sistema aproximou os integrantes da mesma equipe, as equipes entre si e os alunos do professor. Além disso, segundo ele, aproximou também os alunos dos projetos:

Foi importante porque muitas vezes o professor e até mesmo os próprios alunos tem um olhar distante do seu projeto. Falta envolvimento.

Já para o professor E, o sistema possibilitou que o processo projetual fosse sistematicamente avaliado, com comentários pontuais, que ajudaram a explicar e justificar a avaliação realizada:

Sim. O que acontece é que a avaliação pode ser diluída durante o semestre e não só no final, e isso é importante com certeza, porque quando você faz a avaliação no final do semestre, dá a nota, posta no sistema. Os alunos recebem só a nota. Não recebem uma 
justificativa, explicação ou comentário, isso fica só para o próximo semestre quando encontro o aluno de novo e digo: "vamos ter essa disciplina, mas vamos falar da outra que acabou”. Com o sistema, o comentário fica registrado lá como avaliação.

Na mesma linha de raciocínio do professor E, Moursund (2004) destaca a importância das TIC na avaliação do processo. Segundo ele, e grande parte dos autores da ABP, a aprendizagem ocorre justamente enquanto alunos desenvolvem suas atividades; portanto, são as atividades que dão sentido ao projeto e que carecem de avaliação. Para Badia e García (2006), o professor pode utilizar os resultados de um projeto para qualificá-lo, porém, é necessário que recorra às atividades realizadas no decorrer do processo, a fim de avaliar a aprendizagem. Dessa forma, pressupõe-se que, no momento em que o Projeto em Ação permitiu que cada atividade fosse avaliada separada e/ou comparativamente, ele adquiriu uma importância significativa na apreciação dos projetos. Para Donnelly (2005), boas ferramentas de avaliação possibilitam que os professores ofereçam respostas coerentes e condizentes com as dúvidas e questionamentos dos alunos, nas situações e momentos oportunos.

Nas entrevistas, o professor $\mathrm{C}$ concordou com o Professor E, descrevendo, ainda, um comparativo com o Google Drive, ferramenta com a qual já estava familiarizado e que utilizava anteriormente com seus alunos:

[...] por causa desta visualização mais fácil, a possibilidade de interação dos alunos com os comentários que eu fiz foi maior do que no Google Drive, porque no Google Drive eu comentava e os alunos só colocavam resolvido, arquivado ou excluido, este tipo de coisa. Já no Projeto em Ação não, pois fica lá o meu comentário, sempre abaixo do que eu estava avaliando. Eles podiam comentar a cerca do meu comentário e ainda avaliar.

Para o professor $\mathrm{C}$, a vantagem do sistema online de gerenciamento de projetos, em relação ao Google Drive, é que, no primeiro, os comentários e as respostas seguem uma configuração que as permite ficarem gravadas e visíveis nos relatórios; desse modo, elas podem ser integradas à documentação dos projetos. Para Larmer e Mergendoller (2010), o acompanhamento constante é importante para que as equipes mantenham o foco do projeto. Segundo os autores, a avaliação faz com que alunos percebam que existem expectativas em relação ao bom desempenho das equipes e que o propósito do empreendimento é a geração de conteúdos e resultados de alta qualidade. Portanto, na opinião dos autores, o envolvimento dos alunos e o constante refinamento e melhoria das atividades são fundamentais.

\section{Conclusões}

A partir da análise dos dados obtidos pelo experimento aqui realizado, pode-se perceber que a ferramenta de avaliação, disponível na plataforma educacional online, permitiu às equipes de alunos uma minuciosa revisão de seus trabalhos e a abertura para os outros alunos observarem e avaliarem seus projetos, comparando-os com os de outras equipes. Já aos professores, o sistema possibilitou o acompanhamento, a orientação e a avaliação dos projetos dos alunos, também a distância. Além disso, o sistema apresenta uma proposta de avaliação contínua e progressiva. Dessa forma, todas as atividades realizadas nos projetos tiveram avaliações pontuais, feitas uma a uma. Com tal forma de avaliação, o professor pode acompanhar e avaliar regularmente, e com grande frequência, a evolução de cada projeto, registrando ponderações em cada uma de suas etapas. Ao responderem aos comentários dos professores, os alunos sinalizaram a resolução dos problemas identificados ou, buscaram informações mais detalhadas sobre 
o assunto. Estabeleceu-se, com isso, um diálogo capaz de persistir até o momento em que a atividade de avaliação chegasse a um nível satisfatório de desenvolvimento.

\section{Referências bibliográficas}

BADIA, A.; GARCÍA, C. Incorporación de las TIC en la ensañanza y el aprendizaje baseados en la elaboración colaborativa de proyectos. RU\&SC. Revista da Universidade e Sociedade do Conhecimento. V. 3 N. 002. Catalunya, Espanha: Universitat Oberta de Catalunya, 2006.

BEGAY, T. et al. Interdisciplinary Project-Based Learning. USA: JLHE -The Journal of Learning in Higher Education. V. 2 Issue 2. Fall 2006.

BOSS, S.; KRAUSS, J. Reinventing project-based learning: your field guide to realworld projects in the digital age. EUA: International Society for Technology in Education (ISTE), 2007.

CRESWELL, J. W. Projeto de Pesquisa: métodos qualitativos, quantitativos e misto. 3. Ed. Porto Alegre: Artmed, 2010.

DONNELLY, R. Using Technology to Support Project and Problem-Based Learning. In Book: BARRET et al. (Org) Handbook of Enquiry and Problem-based Learning: Irish Case Studies an International Perspectives. Ireland: AISHE, 2005.

GIL, A. C. Métodos e Técnicas de Pesquisa Social. 6. Ed. São Paulo: Atlas, 2009.

GONZALEZ, G.;DE LA ROSA , J. L.; MONTANER, M. Embedding Emotional Context Inrecommender Systems. In The 20th International Florida Artificial Intelligence Research Society Conference-Flairs, Key West, Florida, 2007.

LARMER, J.; MERGENDOLLER J. R. 8 Essentials for Project-Based Learning. USA: BIE EL - Education Leadership. September 2010 V. 68 N. 1. Disponível em www.ascd.org. Acessado em 12/09/2012.

MARKHAM, T. Project based learning design and coaching guide: expert tools for innovation and inquiry for K-12 educators. Califórnia: HeartIQ Press, 2012.

MARKHAM, T, et al. In: BUCK INSTITUTE FOR EDUCATION. Aprendizagem Baseada em Projetos - guia para professores de ensino fundamental e médio - $2^{\mathrm{a}}$ ed. Porto Alegre: Editora Artmed, 2008.

MEURER, H.; SZABLUK, D. PROJETO E: Metodologia Projetual para Desenho de Ambientes Dígito-Virtuais. In: VAN DER LINDEN, J. C. S.; MARTINS, R. F. F (Orgs.). Pelos Caminhos do Design. Rio de Janeiro: Editora Rio Books, 2012.

MEURER, H. Ferramenta de gerenciamento e recomendação como recurso na aprendizagem baseada em projeto em design. Tese de Doutorado em Informática na Educação - UFRGS, 2014.

MILENTIJEVIC, I. et al. Version Control in Project-Based Learning. Computer and Education: December 2006. Disponível em www.sciencedirect.com. Acessado em 06/09/2012.

MOURSUND, D. El Aprendizaje por Proyectos Utilizando las Tecnologías de la Información y las Comunicaciones. Eduteka, 2004.

SAMPIERI, R. H.; COLLADO, C. F.; LUCIO, M. del P. B. Metodologia de Pesquisa. 5. ed. Porto Alegre, RS: Editora Penso, 2013.

SCHWALM, J.; TYLEK, K. S. Systemwide Implementation of Project-based

Learning. Journal Afterschool Matters. Number 15, Spring 2012. 